\title{
Prognostic value of decreased long non-coding RNA TUSC7 expression in some solid tumors: a systematic review and meta- analysis
}

\author{
Na Li ${ }^{1}$, Meilan Yang ${ }^{1}$, Ke Shi' ${ }^{2}$ and Wei Li \\ ${ }^{1}$ Department of Pathology, The First Affiliated Hospital of Hunan University of Medicine, Huaihua, Hunan Province, China \\ ${ }^{2}$ Department of Geriatrics, Xiangya Hospital of Central South University, Changsha, Hunan Province, China \\ Correspondence to: Wei Li, email: xylw2015@csu.edu.cn \\ Keywords: TUSC7, cancer, clinical outcome, prognosis \\ Received: April 18, $2017 \quad$ Accepted: May 29, 2017 \\ Published: June 15, 2017 \\ Copyright: Li et al. This is an open-access article distributed under the terms of the Creative Commons Attribution License 3.0 (CC BY 3.0 ), \\ which permits unrestricted use, distribution, and reproduction in any medium, provided the original author and source are credited.
}

\section{ABSTRACT}

Accumulating evidences indicated that tumor suppressor candidate 7 (TUSC7) is a putatively tumor suppressor gene in various tumors. We carried out current systematic review and meta-analysis to explore the decreased expression of TUSC7 associate with prognostic and clinicopathological characteristic in cancer patients. A literature collection search in the online electronic databases PubMed, Embase, Web of Science, and CNKI was conducted to obtain eligible studies (up to February 20, 2017). A total of nine studies comprise 757 patients were identified and included in present meta-analysis based on the selection and inclusion criteria. Overall, low expression of TUSC7 was associated with significantly unfavorable overall survival (OS) (HR $=2.90$, 95\% CI: 2.12-3.98, $P<0.001$ ), disease free survival (DFS) (HR $=2.00,95 \%$ CI: 1.49-2.68, $P<0.001$ ) and disease-specific survival (DSS) ( $\mathrm{HR}=2.57,95 \% \mathrm{CI}$ : $1.23-$ $5.39, P=0.012)$ in tumors patients. Moreover, we also found that down-regulation of TUSC7 associated with distant metastasis ( $O R=2.85,95 \% \mathrm{CI}: 1.46-5.55, P=0.002)$ and larger tumor size (OR $=0.41,95 \% \mathrm{CI}: 0.23-0.72, P=0.002)$. Our meta-analysis demonstrated that cancers patients detected with low TUSC7 expression were more prone to develop distant metastasis. TUSC7 might act as a potentially and promising common prognostic markers in some solid tumors.

\section{INTRODUCTION}

Numerous studies have indicated that long noncoding RNAs (lncRNAs) are dysregulation in a variety of diseases, including cancer [1-5]. LncRNAs participate in regulating a wide range of biological processes at transcriptional and posttranscriptional levels [6], which play a key role in tumor genesis, progression and prognosis of cancers [2, 7-9]. Tumor suppressor candidate 7 (TUSC7), also called LSAMP antisense RNA3 (LSAMP-AS3) or lncRNA LOC285194, is a newly determined lncRNA, comprising 4 exons with length of about $2.1 \mathrm{~kb}$ and is situated at chromosome region of 3q13.31 [10]. It was first reported as a decreased expression gene in human osteosarcoma; depleting this lncRNA contributed to normal osteoblasts proliferation by regulating cell apoptotic and cell cycle transcripts as well as VEGF receptor 1 [10]. In addition, lncRNA TUSC7 serve as a p53-regulated tumor suppressor in gastric and colon cancer cells, in part by inhibiting miR-23b and miR211 to inhibit cell growth, respectively [11-13]. Thence, TUSC7 is considered to be a tumor suppressor gene.

For the last 5 years, many reports have revealed that decreased TUSC7 expression is correlated with unfavorable overall survival (OS) in various tumors, including non-small-cell lung cancer (NSCLC) [7], colorectal cancer (CRC) [13, 14], esophageal squamous cell carcinoma (ESCC) [15], osteosarcoma (OSA) [16] and so on. Besides, low expression of TUSC7 are poor prognostic factors for disease free survival (DFS) in human gastric cancer (GC) [12], hepatocellular carcinoma (HCC) [17], CRC [14], ESCC [15], as well as NSCLC [7]. 
Studies also continue to indicate that TUSC7 loss plays a role in the poor disease-specific survival (DSS) in patients with gastric cancer [12] and colorectal cancer [14]. Furthermore, decreased TUSC7 expression is also related to tumor clinical characteristics [18, 19]. In addition, serum TUSC7 level displayed a high diagnostic value for patients with colorectal cancer [20]. These results are consistent with lncRNA TUSC7 act as a potential common tumor suppressor and prognosis marker.

However, because of the limitations associated with the research design and sample size, single study may be inaccurate and inadequate. As such, it is necessary to systematically explore the potential clinical values of TUSC 7 in cancers. Thus far, no meta-analysis has yet been conducted to assess the relation between TUSC7 expression and clinical outcomes in various tumors. Therefore, we collected all relevant publications and performed present systematic review and meta-analysis to detect the clinical values of TUSC7 expression level in various tumors. We mainly discussed the expression of TUSC7 associate with prognosis, metastasis and clinicopathological characteristics of cancer patients. It aimed to more precisely evaluate the association between TUSC7 expression and clinical consequence of human cancer.

\section{RESULTS}

\section{Study characteristics}

As shown in the flowchart (Figure 1), a total of 77 reports were searched from Embase, Web of Science, PubMed, and CNKI. After the duplicates were excluded, 36 records were preserved. After reviewing the title and abstracts, 20 records were removed. After further inspection of the full text carefully, a total of 9 studies were ultimately identified according to the criteria [7, 12-19]. The 9 eligible studies comprise 757 patients and all came from China. Among these cancers included in this meta-analysis derived from eight different tumor types: pancreatic ductal adenocarcinoma [19], gastric cancer (GC) [12], esophageal squamous cell carcinoma (ESCC)[15], osteosarcoma (OSA) [16], hepatocellular carcinoma (HCC) [17], non-small-cell lung cancer (NSCLC) [7], colorectal cancer (CRC) [13, 14], and Glioma [18]. All of the TUSC7 expression level were detected by qRT-PCR and divided into high expression and low expression groups. All tumor patients were diagnosed based on pathology. The main characteristics of the include studies were summarized in Table 1.

\section{Meta-analysis results}

\section{Association between TUSC7 and OS}

The relationship between the expression level of TUSC7 and overall survival (OS) was detected in seven researches including 598 patients (Table 1). The fixed effects model was applied to calculate the overall hazard ratios (HRs) because of no heterogeneity among studies $\left(\mathrm{I}^{2}=0.0 \%, P=0.991\right)$. The pooled result $(\mathrm{HR}=2.90,95 \%$ CI: $2.12-3.98, P<0.001)$ indicated that decreased TUSC7 expression exhibited a significantly shorter OS than those with high TUSC7 expression (Figure 2). Consequently, decreased TUSC7 expression associated with a worse survival in tumor patients.

\section{Association between TUSC7 and DFS/DSS}

Five studies include a total of 488 patients reported HRs for disease free survival (DFS). No significant heterogeneity across these studies $\left(\mathrm{I}^{2}=38.7 \%, P=0.163\right)$, so the fixed-effects model was used to pool the HRs. The aggregated results revealed that the low TUSC7 expression was significantly correlation with poor DFS $(\mathrm{HR}=2.00$, 95\% CI: 1.49-2.68, $P<0.001$ ) (Figure 3). Only two eligible articles reporting a total of 159 patients were offered data to analyze disease-specific survival (DSS). Because of the small heterogeneity $\left(\mathrm{I}^{2}=0 \%, P=0.880\right)$, the fixed effect model was adopted. The summarized result indicated decreased TUSC7 expression represents a poor clinical outcome for DSS (HR $=2.57,95 \% \mathrm{CI}$ : $1.23-5.39$, $P=0.012)$ (Figure 3).

\section{Associations between TUSC7 and clinicopathological parameters}

From the pooled results showed in Table 2, it found that decreased TUSC7 expression was positively correlated with distant metastasis ( $\mathrm{OR}=2.85,95 \% \mathrm{CI}$ : 1.46-5.55, $P=0.002$, fixed effects model) and tumor size $(\mathrm{OR}=0.41,95 \% \mathrm{CI}: 0.23-0.72, P=0.002$, fixed effects model). However, no significant correlations were observed between the decreased TUSC7 expression and other clinicopathologic parameters involving lymph node metastasis, gender, clinical stage and invade depth $(P>0.05)$. Due to insufficient data, we were unable to detect the association between low TUSC7 expression and other clinicopathological factors.

\section{Sensitivity analysis}

To evaluate the robustness of the summarized results in this study, a sensitivity analysis was conducted by successively excluding each individual study from the pooled analysis. The result of the relationship between TUSC7 expression and OS or DFS was not significantly influenced after excluding any study, suggesting that the results were robust (Figure 4). Considering that the small number of studies, sensitivity analysis of other groups has not been carried out.

\section{Evaluation of publication bias}

The publication bias of this meta-analysis was evaluated by Begg's funnel plot analysis. There was no 
obvious publication bias in both DFS group $(\operatorname{Pr}>|\mathrm{z}|=$ 0.462) and OS group $(\operatorname{Pr}>|z|=0.133)$ by Begg's test (Figure 5).

\section{DISCUSSION}

A lot of studies have proved that dysregulated expression of lncRNAs is closely related to tumorigenesis and cancer progression [21-24]. TUSC7 was a newly identified ncRNA gene, reported to be decreased expression in various cancer cells and tumor tissues as a tumor suppressor [7, 13, 16-19]. TUSC7 influences the proliferation, apoptosis, and cell cycle transcripts in normal osteoblasts [10]. Moreover, by repressing miR$23 \mathrm{~b}$ transcription, TUSC7 inhibited cellular proliferation, migration and invasion and promoted cellular apoptosis in gastric cancer and glioma cells $[12,18]$. Additionally, TUSC7 acts as a molecular sponge of miR-10a and suppresses EMT through decrease the expression of Eph tyrosine kinase receptor A4 in human hepatocellular carcinoma [17]. In addition, previous studies have reported that down-regulation of TUSC7 was associated with chemoresistance in ESCC [15]. Therefore, further explore the relationship between TUSC7 and cancer is absolutely necessary.

Here we implemented present meta-analysis to evaluate the relationship of TUSC7 expression levels with prognosis results and clinicopathological parameter in cancer patients. To the best of our knowledge, this is the first meta-analysis offering comprehensive insights into the prognostic value of TUSC7 in human cancer. There were altogether 9 eligible studies met the selection requirements in our meta-analysis. The survival data comprised OS, DFS, DSS. The results indicated that decreased TUSC7 expression was significantly related to unfavorable clinical prognosis in patients with various tumor types. Firstly, the pooled results demonstrated that the patients with low TUSC7 expression exhibited a shorter OS than those with high TUSC7 expression. Secondly, the patients with decreased TUSC7 significantly related to unfavorable DFS

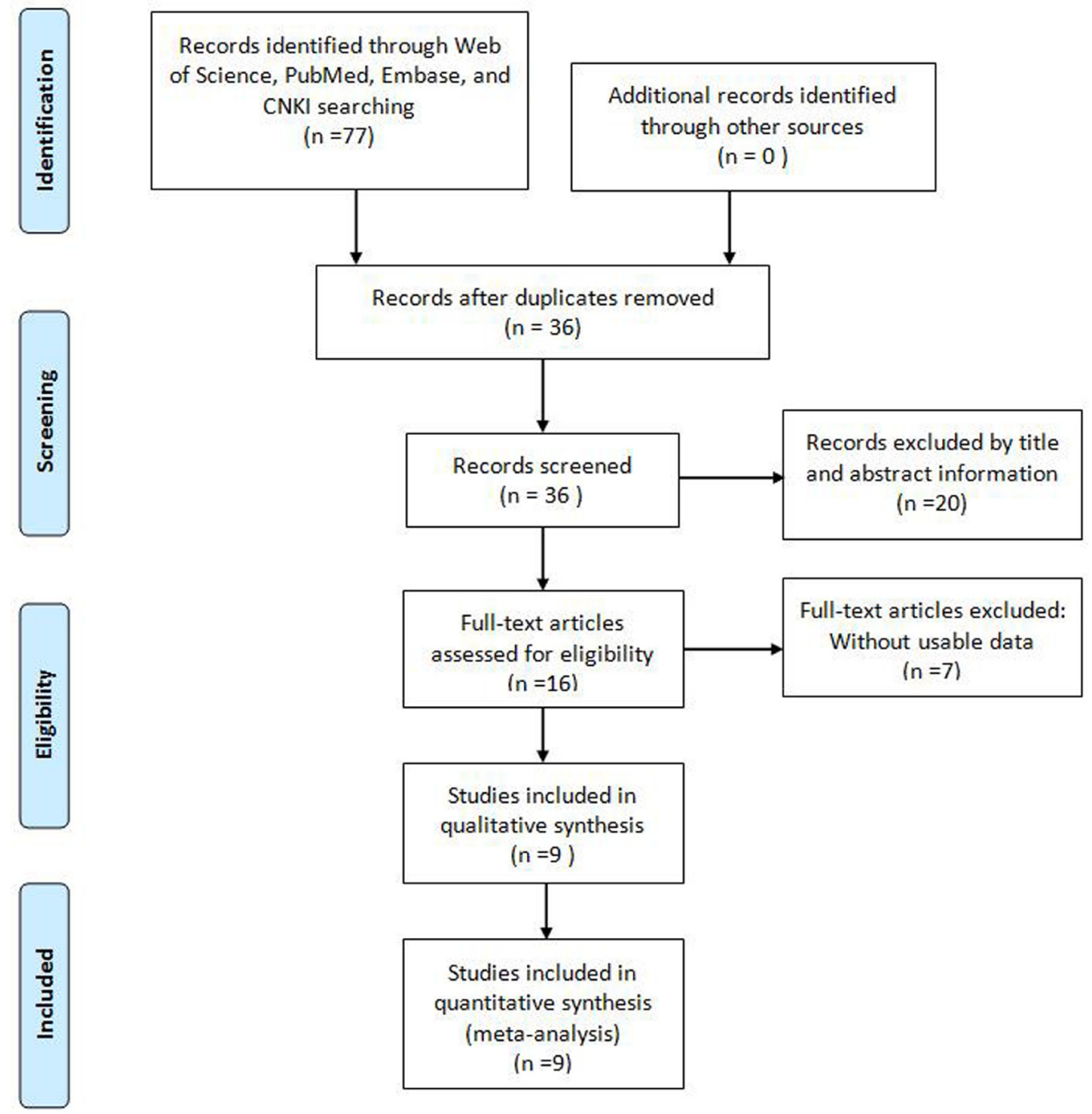

Figure 1: Flow diagram of the literature search and selection. 
Table 1: Main characteristics of the include studies for prognostic

\begin{tabular}{|c|c|c|c|c|c|c|c|c|}
\hline Study & Region & $\begin{array}{l}\text { Tumor } \\
\text { type }\end{array}$ & $\begin{array}{c}\text { Sample } \\
\text { size }\end{array}$ & $\begin{array}{c}\text { Test } \\
\text { method }\end{array}$ & Cut-off & $\begin{array}{c}\text { Outcome } \\
\text { measure }\end{array}$ & $\begin{array}{c}\text { HR } \\
\text { estimation }\end{array}$ & $\begin{array}{c}\text { Follow-up } \\
\text { (months) }\end{array}$ \\
\hline Qi 2013 & China & $\mathrm{CRC}$ & 81 & qRT-PCR & mean value & DFS/DSS & Directly & $\sim 60$ \\
\hline Ding 2014 & China & PDAC & 85 & qRT-PCR & $\begin{array}{l}\text { mean } \\
\text { value }\end{array}$ & OS & Directly & $\sim 60$ \\
\hline Tong 2014 & China & ESCC & 142 & qRT-PCR & $\begin{array}{l}\text { median } \\
\text { value }\end{array}$ & OS/DFS & Directly & $\sim 36$ \\
\hline Qi 2015 & China & $\mathrm{GC}$ & 78 & qRT-PCR & mean value & DFS/DSS & Directly & Over 60 \\
\hline Cong 2016 & China & OSA & 82 & qRT-PCR & NA & OS & Directly & Over 110 \\
\hline Shang 2016 & China & Glioma & 39 & qRT-PCR & NA & OS & Directly & $\sim 40$ \\
\hline $\begin{array}{c}\text { Wang Y } \\
2016\end{array}$ & China & $\mathrm{HCC}$ & 75 & qRT-PCR & mean value & OS/DFS & Directly & $\sim 36$ \\
\hline $\begin{array}{c}\text { Wang Z } \\
2016\end{array}$ & China & NSCLC & 112 & qRT-PCR & $\begin{array}{l}\text { median } \\
\text { value }\end{array}$ & OS/DFS & Directly & Over 60 \\
\hline Xu 2017 & China & $\mathrm{CRC}$ & 63 & qRT-PCR & mean value & OS & Directly & Over 100 \\
\hline
\end{tabular}

PDAC: pancreatic ductal adenocarcinoma; GC: gastric cancer; ESCC: esophageal squamous cell carcinoma; OSA: osteosarcoma; HCC: hepatocellular carcinoma; NSCLC: non-small-cell lung cancer; CRC: colorectal cancer; OS: overall survival; DFS: disease free survival; DSS: disease-specific survival; qRT-PCR: quantitative real-time PCR; NA: not available.

or DSS. These results showed that TUSC7 could serve as a potential independent predictive biomarker for OS or DFS or DSS in tumor patients. Thirdly, the aggregated results showed that decreased TUSC7 expression was positively correlated with distant metastasis and larger tumor size. In other words, cancer patients with low TUSC7 expression in tumor tissues were more prone to develop DM. Finally, no significant correlations were observed between the decreased TUSC7 expression and lymph node metastasis or gender or clinical stage or invade depth. However, some studies reported that decreased expression of TUSC7 was closely associated with more lymphnode metastasis

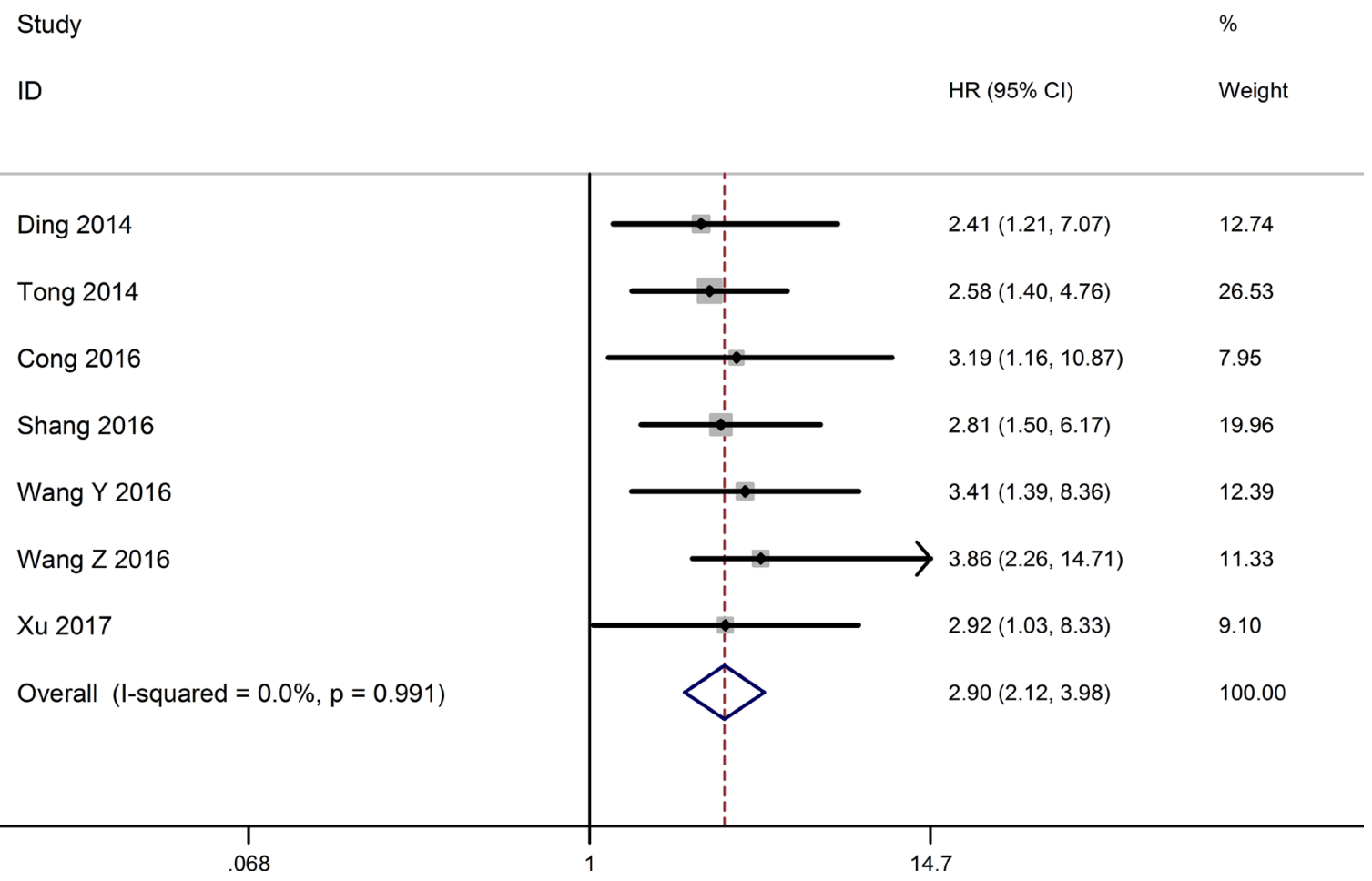

Figure 2: Forest plot for the relationships between decreased TUSC7 expression and OS. 
$[14,15,19]$. To explore whether the heterogeneity affect the pooled results, we found decreased TUSC7 expression was positively associated with LNM $(\mathrm{OR}=3.29$, 95\% CI: 2.05-5.28, $P<0.001$, fixed effects model) after exclude a datasets of LNM from Wang et al. [7]. Because of the small size of the study, this conclusion may be insufficiently convincing. Therefore, further researches are needed to confirm this completion.

Although TUSC7 was found to be significantly correlated with the prognosis of cancer patients, some limitations should be concerned for explaining the results of this meta-analysis. For instance, only nine studies included in our meta-analysis and patients were all Asians from China, thence, our results may be suitable only to this Chinese population. Additionally, the cut-off values of decreased TUSC7 expression not consistent. Finally, there was significant heterogeneity in some clinicopathological parameters analysis. Thus, the results of this meta-analysis should be confirmed by future studies with well-designed and larger-size.

In conclusion, our meta-analysis offers evidence that low TUSC7 expression is a risk factor for distant metastasis in diverse cancers. TUSC7 could act as a potentially and promising prognostic markers in human some solid tumors.

\section{MATERIALS AND METHODS}

\section{Publication search}

We searched online electronic databases Embase, PubMed, Web of Science and CNKI (up to February 20, 2017 ) to obtain the publications about lncRNA TUSC7 expression. The search terms were as follows: "TUSC7" [Title/Abstract] OR "tumor suppressor candidate 7" [Title/Abstract] OR “LOC285194” [Title/Abstract] OR "LSAMP-AS3" [Title/Abstract] OR "LSAMP antisense RNA3" [Title/Abstract]. Only include English or Chinese publications in this study.

\section{Study inclusion and exclusion criteria}

The inclusion criteria of present meta-analysis as follows: (1) article researched the association with TUSC7 expression and cancer prognosis; (2) cancer patients were divided into two groups: high TUSC7 expression or low TUSC7 expression; (3) reporting related clinical parameters, such as lymph node metastasis and distant metastasis; (4) providing sufficient data for the computation of OR, HR and corresponding 95\% CI.
Study

ID
$\%$

$\mathrm{HR}(95 \% \mathrm{Cl})$

Weight

\begin{tabular}{|c|c|c|c|}
\hline \multicolumn{4}{|l|}{ DFS } \\
\hline Qi 2013 & $\rightarrow$ & $1.24(1.05,4.28)$ & 17.41 \\
\hline Tong 2014 & . & $2.93(1.66,5.18)$ & 26.50 \\
\hline Qi 2015 & & $2.86(1.84,9.77)$ & 12.28 \\
\hline Wang Z 2016 & $\rightarrow$ & $1.44(1.22,3.40)$ & 32.49 \\
\hline Wang Y 2016 & & $2.93(1.23,6.99)$ & 11.33 \\
\hline Subtotal $(I-$ squared $=38.7 \%, p=0.163)$ & & $2.00(1.49,2.68)$ & 100.00 \\
\hline \multicolumn{4}{|l|}{ DSS } \\
\hline Qi2013 & & $2.97(0.23,12.05)$ & 13.90 \\
\hline Qi 2015 & & $2.52(1.13,5.58)$ & 86.10 \\
\hline Subtotal $(I-$ squared $=0.0 \%, p=0.880)$ & & $2.57(1.23,5.39)$ & 100.00 \\
\hline
\end{tabular}

Figure 3: Forest plot for the relationships between decreased TUSC7 expression and DFS/DSS. 
Table 2: Odds ratio for the association between decreased TUSC7 expression and clinicopathological parameters

\begin{tabular}{|c|c|c|c|c|c|c|}
\hline \multirow{2}{*}{ Clinicopathological parameter } & \multirow{2}{*}{ Patients size } & \multirow{2}{*}{ OR (95\% CI) } & \multirow{2}{*}{$P$ value } & \multicolumn{3}{|c|}{ Heterogeneity } \\
\hline & & & & $I^{2}$ & $\boldsymbol{P}_{h}$ & Model \\
\hline $\begin{array}{l}\text { Gender } \\
\text { (Male vs. Female) }\end{array}$ & 495 & $0.74(0.51-1.06)$ & 0.102 & $0.0 \%$ & 0.456 & Fixed effects \\
\hline $\begin{array}{l}\text { Clinical stage } \\
\text { ( I/II vs. III/IV) }\end{array}$ & 495 & $0.84(0.23-3.14)$ & 0.800 & $91.1 .0 \%$ & $<0.001$ & $\begin{array}{l}\text { Random } \\
\text { effects }\end{array}$ \\
\hline $\begin{array}{l}\text { Lymph node metastasis } \\
\text { (Yes vs. No) }\end{array}$ & 420 & $2.31(0.92-5.82)$ & 0.076 & $80.2 \%$ & 0.002 & $\begin{array}{l}\text { Random } \\
\text { effects }\end{array}$ \\
\hline Distant metastasis (Yes vs. No) & 223 & $2.85(1.46-5.55)$ & 0.002 & $0.0 \%$ & 0.644 & Fixed effects \\
\hline $\begin{array}{l}\text { Depth of invasion } \\
\text { (T1/T2 vs. T3/T4) }\end{array}$ & 308 & $0.80(0.49-1.29)$ & 0.358 & $0.0 \%$ & 0.725 & Fixed effects \\
\hline $\begin{array}{l}\text { Tumor size } \\
(<5 \mathrm{~cm} \text { vs. } \geq 5 \mathrm{~cm})\end{array}$ & 217 & $0.41(0.23-0.72)$ & 0.002 & $39.5 \%$ & 0.199 & Fixed effects \\
\hline
\end{tabular}
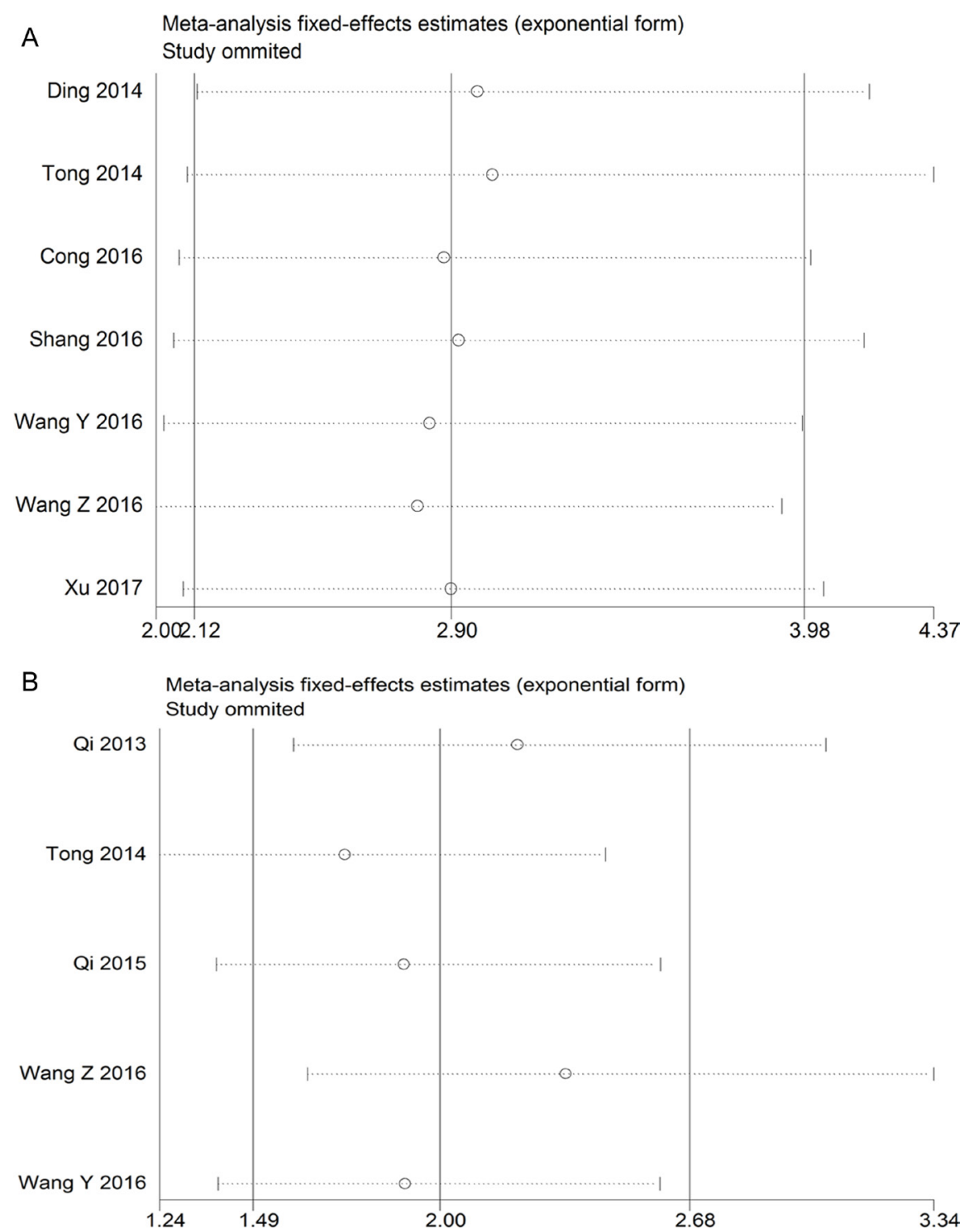

Figure 4: The sensitivity analysis for the meta-analysis of OS or DFS in tumor patients. (A) OS group; (B) DFS group. 
Exclusion criteria of this meta-analysis are following: (1) nonhuman research; (2) duplicate publications; (3) case reports, letters, expert opinions, editorials and reviews; (4) studies without available data.

\section{Quality assessment and data extraction}

Two investigators ( $\mathrm{Na} \mathrm{Li}$ and Wei Li) using the Newcastle-Ottawa Quality Assessment Scale (NOS) to assess the quality of all eligible studies independently, which were reported in previously studies [25, 26]. All included studies were considered to be of high quality based on NOS. The data from each eligible study were extracted and reviewed by two authors (Wei Li and Ke Shi) independently. Disagreements were discussed with third researcher $(\mathrm{Na} \mathrm{Li})$ to reach a consensus. The following information from every study was collected: first author's name, publication date, study region, tumor type, detection method of TUSC7 expression, criteria of TUSC7 high expression, total patients amount, clinicopathological parameter, and survival analysis, follow-up period, HR and corresponding 95\% CI. If the available survival data not shown in articles, corresponding authors were contacted to collect these data or extracted from graphical survival plots and HRs were estimated.

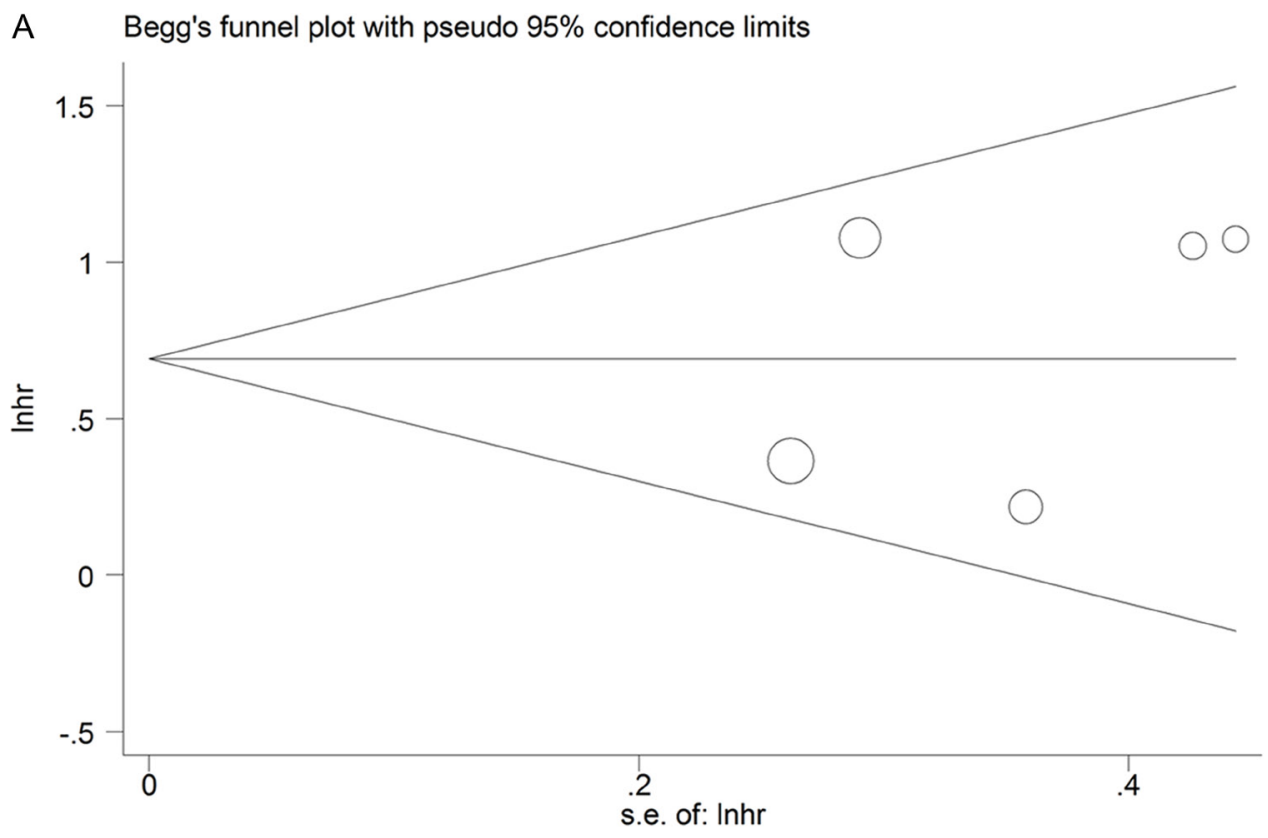

B Begg's funnel plot with pseudo 95\% confidence limits

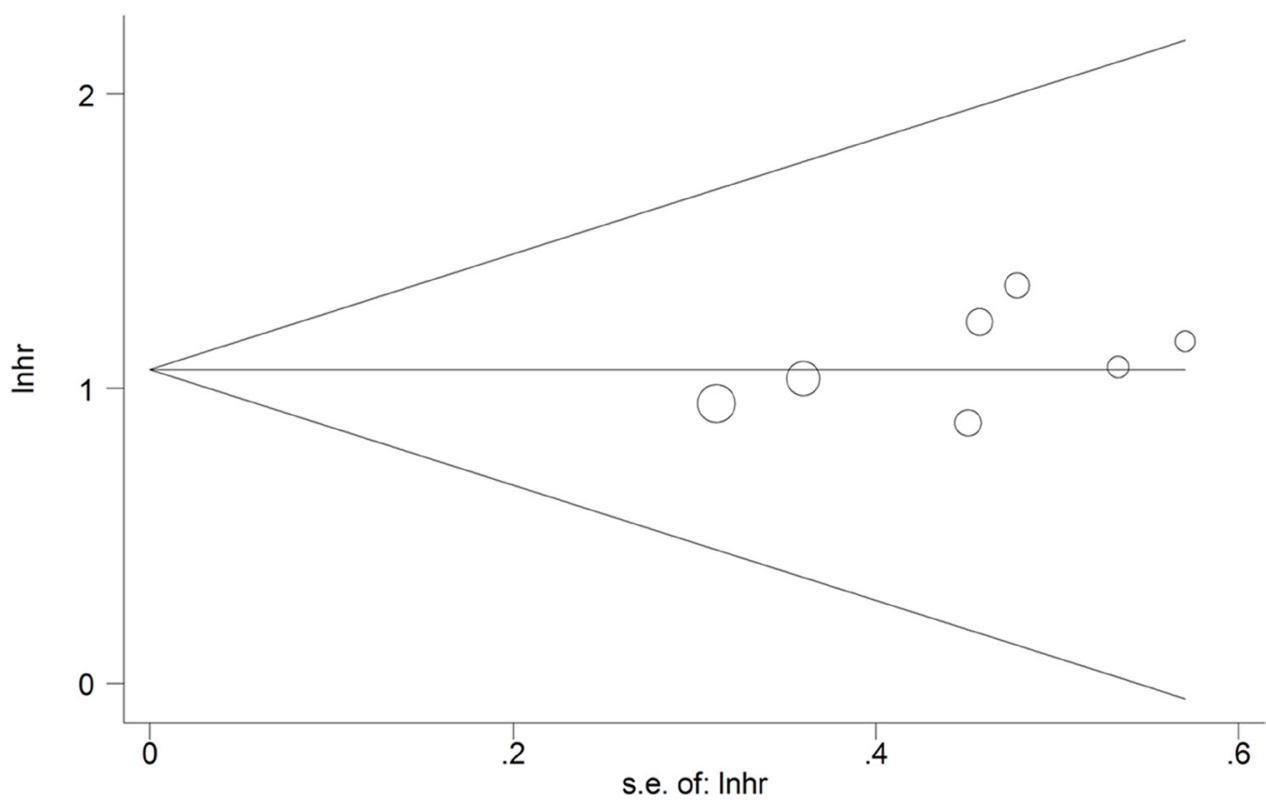

Figure 5: Funnel plot analysis of potential publication bias for meta-analysis. (A) DFS group; (B) OS group. 


\section{Statistical methods}

All statistical analysis of the present study was conducted by STATA SE 12.0 software (Stata, College Station, Texas). The heterogeneity of pooled HRs or ORs among included studies was detected using the Q-statistic test and chi-squared based. The fixed-effects model was used to pool the results when the included studies with small heterogeneity $\left(\mathrm{I}^{2}<50 \%, P>0.1\right)$. Otherwise, a random effects model was applied $\left(\mathrm{I}^{2}>50 \%, P<0.1\right)$. A sensitivity analysis was executed to evaluate the robustness of the overall results. The "Begg's funnel plot" was used to assess potential publication bias. All the $P$-values less than 0.05 were regarded as statistical significance.

\section{ACKNOWLEDGMENTS AND FUNDING}

This work was supported by funding from the Key Program of Hunan province Science and Technology Hall (2015SK20662).

\section{CONFLICTS OF INTEREST} interests.

All authors declare that there is no conflict of

\section{REFERENCES}

1. Qian Y, Liu D, Cao S, Tao Y, Wei D, Li W, Li G, Pan X, Lei D. Upregulation of the long noncoding RNA UCA1 affects the proliferation, invasion, and survival of hypopharyngeal carcinoma. Mol Cancer. 2017; 16:68.

2. Adams BD, Parsons C, Walker L, Zhang WC, Slack FJ. Targeting noncoding RNAs in disease. J Clin Invest. 2017; 127:761-771

3. Beermann J, Piccoli MT, Viereck J, Thum T. Noncoding RNAs in Development and Disease: Background, Mechanisms, and Therapeutic Approaches. Physiol Rev. 2016; 96:1297-1325.

4. Parikshak NN, Swarup V, Belgard TG, Irimia M, Ramaswami G, Gandal MJ, Hartl C, Leppa V, Ubieta LT, Huang J, Lowe JK, Blencowe BJ, Horvath S, et al. Genomewide changes in lncRNA, splicing, and regional gene expression patterns in autism. Nature. 2016; 540:423-427.

5. Chang S, Chen B, Wang X, Wu K, Sun Y. Long non-coding RNA XIST regulates PTEN expression by sponging miR181a and promotes hepatocellular carcinoma progression. BMC Cancer. 2017; 17:248.

6. Chen LL. Linking Long Noncoding RNA Localization and Function. Trends Biochem Sci. 2016; 41:761-772.

7. Wang $Z$, Jin $Y$, Ren $H$, Ma X, Wang B, Wang Y. Downregulation of the long non-coding RNA TUSC7 promotes NSCLC cell proliferation and correlates with poor prognosis. Am J Transl Res. 2016; 8:680-687.
8. Chandra Gupta S, Nandan Tripathi Y. Potential of long non-coding RNAs in cancer patients: From biomarkers to therapeutic targets. Int J Cancer. 2017; 140:1955-1967.

9. Li X, Cao Y, Gong X, Li H. Long noncoding RNAs in head and neck cancer. Oncotarget. 2017; 8:10726-10740. doi: 10.18632/oncotarget.12960.

10. Pasic I, Shlien A, Durbin AD, Stavropoulos DJ, Baskin B, Ray PN, Novokmet A, Malkin D. Recurrent focal copynumber changes and loss of heterozygosity implicate two noncoding RNAs and one tumor suppressor gene at chromosome 3q13.31 in osteosarcoma. Cancer Res. 2010; 70:160-171.

11. Liu Q, Huang J, Zhou N, Zhang Z, Zhang A, Lu Z, Wu F, Mo YY. LncRNA loc285194 is a p53-regulated tumor suppressor. Nucleic Acids Res. 2013; 41:4976-4987.

12. Qi P, Xu MD, Shen XH, Ni SJ, Huang D, Tan C, Weng WW, Sheng WQ, Zhou XY, Du X. Reciprocal repression between TUSC7 and miR-23b in gastric cancer. Int J Cancer. 2015; 137:1269-1278.

13. $\mathrm{Xu}$ J, Zhang $\mathrm{R}$, Zhao J. The Novel Long Noncoding RNA TUSC7 Inhibits Proliferation by Sponging MiR-211 in Colorectal Cancer. Cell Physiol Biochem. 2017; 41:635-644.

14. Qi P, Xu MD, Ni SJ, Huang D, Wei P, Tan C, Zhou XY, Du X. Low expression of LOC285194 is associated with poor prognosis in colorectal cancer. J Transl Med. 2013; 11:122.

15. Tong YS, Zhou XL, Wang XW, Wu QQ, Yang TX, Lv J, Yang JS, Zhu B, Cao XF. Association of decreased expression of long non-coding RNA LOC285194 with chemoradiotherapy resistance and poor prognosis in esophageal squamous cell carcinoma. J Transl Med. 2014; 12:233.

16. Cong M, Li J, Jing R, Li Z. Long non-coding RNA tumor suppressor candidate 7 functions as a tumor suppressor and inhibits proliferation in osteosarcoma. Tumour Biol. 2016; 37:9441-9450.

17. Wang Y, Liu Z, Yao B, Dou C, Xu M, Xue Y, Ding L, Jia Y, Zhang H, Li Q, Tu K, Jiao Y, Liu Q, et al. Long non-coding RNA TUSC7 acts a molecular sponge for miR-10a and suppresses EMT in hepatocellular carcinoma. Tumour Biol. 2016; 37:11429-11441.

18. Shang C, Guo Y, Hong Y, Xue YX. Long Non-coding RNA TUSC7, a Target of miR-23b, Plays Tumor-Suppressing Roles in Human Gliomas. Front Cell Neurosci. 2016; 10:235.

19. Ding YC, Yu W, Ma C, Wang Q, Huang CS, Huang T. Expression of long non-coding RNA LOC285194 and its prognostic significance in human pancreatic ductal adenocarcinoma. Int J Clin Exp Pathol. 2014; 7:8065-8070.

20. Wang C, Yu J, Han Y, Li L, Li J, Li T, Qi P. Long noncoding RNAs LOC285194, RP11-462C24.1 and Nbla12061 in serum provide a new approach for distinguishing patients with colorectal cancer from healthy controls. Oncotarget. 2016; 7:70769-70778. doi: 10.18632/oncotarget.12220.

21. Bian D, Shi W, Shao Y, Li P, Song G. Long non-coding RNA GAS5 inhibits tumorigenesis via miR-137 in melanoma. Am J Transl Res. 2017; 9:1509-1520. 
22. Shi L, Peng F, Tao Y, Fan X, Li N. Roles of long noncoding RNAs in hepatocellular carcinoma. Virus Res. 2016; 223:131-139.

23. Bartonicek N, Maag JL, Dinger ME. Long noncoding RNAs in cancer: mechanisms of action and technological advancements. Mol Cancer. 2016; 15:43.

24. Dong J, Xu J, Wang X, Jin B. Influence of the interaction between long noncoding RNAs and hypoxia on tumorigenesis. Tumour Biol. 2016; 37:1379-1385.
25. Xiao J, Hu CP, He BX, Chen X, Lu XX, Xie MX, Li W, He SY, You SJ, Chen Q. PTEN expression is a prognostic marker for patients with non-small cell lung cancer: a systematic review and meta-analysis of the literature. Oncotarget. 2016; 7:57832-57840. doi: 10.18632/oncotarget.11068.

26. Xiao J, Zou Y, Chen X, Gao Y, Xie M, Lu X, Li W, He B, He S, You S, Chen Q. The Prognostic Value of Decreased LKB1 in Solid Tumors: A Meta-Analysis. PLoS One. 2016; 11:e0152674. 